AGNIESZKA DEJNAKA

ORCID: 0000-0001-6222-3187

Wyższa Szkoła Bankowa we Wrocławiu

\title{
Design a fitness — nowe trendy
}

DOI: $10.19195 / 2083-7763.9 .8$

\section{Wstęp}

Design do tej pory był kojarzony w głównej mierze ze sferą sztuki i architektury. Mimo to określenie „design” od lat 60 . XX wieku z powodzeniem zaczęło przenikać do języka biznesu na całym świecie, odnosząc się do zarządzania i opisując wpływ bodźców wizualnych na zachowania nabywców (Celaschi, Celi, Garcia 2011, s. 88).

Design pełni ważną funkcję w rozwoju produktu oraz kreacji marki, tym samym ma ogromne znaczenie dla przedsiębiorstwa. Jego zasadniczą wartość upatruje się we właściwym przyczynianiu się do podnoszenia produktywności firm. Określenie jego korzyści w tym zakresie było celem badań prowadzonych przez Design Council w Wielkiej Brytanii. Wskazano, że design:

- pomaga zwiększać udział w rynku,

- zwiększa obroty,

- pomaga tworzyć nowe produkty i usługi,

- pomaga zwiększyć zatrudnienie (Alonso, Plasencia, Kint 2012, s. 76).

Raport przygotowany przez Design Council pokazuje, że dzięki strategiom opartym na designie odnotowano wzrost udziału rynkowego w handlu detalicznym i hurtowym oraz w sektorze wypoczynkowym odpowiednio o 6,9\% i 7,2\%. Prawie połowa firm (46\%), która w swych strategiach wykorzystuje design, w ciągu 12 miesięcy odnotowała wzrost obrotów o wartość większą, niż wyniosły wydatki w tym samym czasie. Przedsiębiorstwa wykorzystujące design opracowują średnio 25 nowych produktów rocznie; przynajmniej dwie trzecie z nich (71\%) wprowadzają na rynek co najmniej jeden produkt, dwa rodzaje usług rocznie oraz zatrudniają średnio ponad 13 osób rocznie (Alonso, Plasencia, Kint 2012, s. 76 n.). 
Design może być fundamentalnym kwantyfikatorem innowacyjnej procedury odnoszącej się do rozwoju. Może stanowić oś całościowej wizji dążeń, oceny osiągalnych środków oraz możliwości ich wykorzystania, a także być fundamentem ustalonych sposobów i sekwencji rozwiązań w celu osiągnięcia właściwego postępu lub rozwiązania priorytetowych zagadnień danego przedsiębiorstwa (Peters 2005, s. 196; Hetzel 2013, s. 154). Firmy, które widzą wzornictwo jako potencjał strategiczny, odchodzą od podejścia teoretycznego polegającego przede wszystkim na właściwym i odpowiednim angażowaniu projektantów jedynie na wybranym etapie procesu tworzenia produktu - nowe podejście zakłada zaangażowanie projektantów od samego początku tego postępowania do jego końca (de Mozota 2003, s. 268).

Design wpływa na zachowania zakupowe konsumentów. W literaturze przedmiotu znaleźć można wiele odmiennych definicji zachowania konsumenta, akcentujących jego różne aspekty. J.F. Engel, R.D. Blackwell i P.W. Mirand określają zachowanie konsumenta jako ogół działań związanych z uzyskiwaniem, użytkowaniem i dysponowaniem produktami wraz z decyzjami poprzedzającymi i warunkującymi te działania (Engel, Blackwell, Mirand 1993, s. 4). Podobnie F. Hansen zachowania konsumenta definiuje jako ogół działań i percepcji składających się na przygotowanie decyzji wyboru produktu, dokonanie wyboru oraz konsumowanie (Hansen 1972, s. 15). Natomiast T. Sztucki twierdzi, że zachowania konsumentów dotyczą działań zmierzających do kupowania i korzystania z zakupionych produktów, łącznie z mechanizmami psychologicznymi i socjologicznymi poprzedzającymi te działania oraz następującymi po nich (Sztucki 1998, s. 423).

Zachowania konsumentów na rynku kształtują się pod wpływem wielu determinant, zarówno stricte ekonomicznych, jak i społecznych i kulturowych - w tym zmian stylu życia na bardziej zdrowy, aktywny. W celu nadążenia za zmianami konsumentów firmy muszą nie tylko śledzić obecne zmiany, lecz także przewidywać przyszłościowe trendy zachowań podmiotów rynkowych. Przez pojęcie "trend" rozumie się istniejący w danym momencie kierunek rozwoju w jakiejś dziedzinie bądź, bardziej ogólnie, monotoniczny składnik zależności badanej cechy od czasu. H. Vejlgaard definiuje trend jako proces zmiany, który jest ujmowany z perspektywy psychologicznej, ekonomicznej lub socjologicznej, mogący mieć charakter krótko- lub długookresowy oraz zasięg regionalny bądź globalny (Vejlgaard 2008, s. 9). Konsumpcja - w całościowym ujęciu - oznacza proces zaspokajania różnorodnych i podlegających zmianie potrzeb ludzkich, obejmujący wszystkie formy zachowania jednostek, związany z uzyskiwaniem i użytkowaniem dóbr i usług, uzależniony od warunków ekonomicznych, kulturowych, społecznych i psychologicznych (Zalega 2012, s. 21).

Obecnie część konsumentów zmienia swoje nawyki żywieniowe oraz związane z aktywnością sportową. Modnie jest być „fit”, odżywiać się zdrowo, mieć karnet 
na siłownię oraz kolekcję ubrań sportowych i gadżetów monitorujących działanie organizmu. Wskazane zmiany powodują, że stawiane są przed nami pytania:

1. Jaka jest rola designu w fitnessie?

2. Jakie są trendy designerskie związane z fitnessem, jakich obszarów dotyczą oraz w jakim kierunku będzie rozwijał się design?

$\mathrm{Na}$ te pytania - mam nadzieję - odpowie niniejszy artykuł, prezentujący trendy w designie fitness.

\section{Rola designu w fitnessie — kluby fitness}

Kluby fitness są pierwszym elementem, który w ostatnich latach przeszedł przeobrażenia - zmiana nastąpiła $\mathrm{w}$ kierunku designu pomieszczeń $\mathrm{w}$ połączeniu $\mathrm{z}$ funkcjonalnością.

Pierwszy trend to design klubów fitness w stylu industrialnym. Wymaga to dysponowania przez właścicieli klubu przemysłową przestrzenią, lokalem loftowym lub zwykłą przestrzenią piwniczną. Design industrialny w klubach fitness to według Branży Fitness.com „odkryte instalacje sufitowe, beton, cegła, surowe drewno czy siatka cięto-ciągniona"1. Takie kluby przyciągają młodych ludzi z korporacji, chcących pokazać się w nowoczesnym otoczeniu.

Kolejnym trendem są kluby fitness w stylu udomowionym. W klubach fitness o designie udomowionym obok sprzętu do ćwiczeń pojawiają się miękkie, kolorowe sofy, domowe lampy i regały. Wyposażenie siłowni w tego rodzaju atrybuty sprawi, że klienci poczują się tu swobodnie. Będzie to również pomagało w nawiązywaniu relacji pomiędzy ćwiczącymi, a w konsekwencji - w budowaniu klubowej społeczności, a to z kolei przekłada się na lojalność klienta. Nastrojowe światło, przyciemnienie dają poczucie intymności i poprawiają komfort ćwiczeń. Przykładem zastosowania takiego designu jest McFit Home of Fitness ${ }^{2}$.

Design nowych studiów McFit Home of Fitness zdecydowanie wykracza poza poziom czysto praktyczny. Swoim wyglądem studio przywodzi na myśl dom obieżyświata. Panuje w nim atmosfera, w której ćwiczący czują się komfortowo jak w domu. Rozmaite style, od street artu, przez etno, aż po sztukę nowoczesną, łączą się w wyjątkowy sposób w jedną koncepcję przestrzenną i oświetleniową. Dodatkowo w klubie znajdują się graffiti lokalnych artystów, barokowe lustra i żyrandole oraz barwne patchworkowe dywany, zapewniające nietypowe, designerskie otoczenie treningowe. Nowy design został opracowany przez prezesa McFIT Global Group Rainera Schallera.

${ }^{1}$ https://www.branzafitness.com/najnowsze-trendy-aranzacja-przestrzeni-klubu-fitness/ (dostęp: 3.03.2019).

${ }^{2}$ McFit Home of Fitness, https://www.mcfit.com/pl/firma/firma/ (dostęp: 15.11.2018). 
Kolejnym, widocznym w 2018 roku, trendem jest projektowanie przestrzeni fitness w stylu biofilicznym.

Jest to styl oparty na ekologicznym projektowaniu — z użyciem materiałów eko, drewna z podkreślonym usłojeniem, forniry, korka oraz czerpaniu inspiracji z przyrody. Osoby korzystające $\mathrm{z}$ siłowni to $\mathrm{w}$ dużej mierze pasjonaci zdrowego trybu życia, tęskniący za przestrzenią $\mathrm{w}$ wielkim mieście, zdrowo się odżywiający — doceniają klub fitness z fototapetami i materiałami naturalnymi. W tych przestrzeniach - według prognoz - w 2019 roku dominować będą instalacje/ fototapety w duże egzotyczne kwiaty, a przeważającym kolorem będzie oceaniczny odcień błękitu oraz jego połączenie z energetyczną fuksją, żółcią czy pomarańczą ${ }^{3}$.

Jak jest rola designu klubu fitness dla konsumenta? Użytkownik, ćwicząc w klubie fitness, powinien odczuwać przyjemność ze sportu, zmagać się ze swoim ciałem oraz wyjść poza „strefę komfortu” fizycznego, gdyż ćwiczenia aerobowe i budujące masę mięśniową wymagają pracy i zmiany trybu życia. Właściciele klubów fitness rozumieją takie potrzeby klientów, ale wiedzą też, że podstawową zasadą jest to, aby sport był przyjemnością oraz oderwaniem się od codziennej rutyny. W związku z tym design klubów sportowych ma zapewnić oderwanie od monotonii i pozwolić konsumentowi pracować nad swoim ciałem w ciekawych wizualnie pomieszczeniach. Poza tym uczęszczanie do designerskiego klubu fitness stało się informacją, którą konsumenci dzielą się w pracy i wśród rodziny. Obecnie "na czasie" jest posiadanie karnetu do modnego klubu fitness, prezentowanie w mediach społecznościowych zdjęć z klubu i kreowanie własnego wizerunku jako osoby aktywnej i prowadzącej zdrowy styl życia. Kluby fitness wychodzą temu naprzeciw, kreując nowy design przestrzeni do aktywnego wypoczynku.

\section{Rola designu w fitnessie — odzież sportowa/fitness}

Kolejną dziedziną rozwoju designu $\mathrm{w}$ fitnessie jest odzież sportowa/fitness. Nowoczesna odzież sportowa musi być nie tylko wygodna i funkcjonalna, lecz także modna i designerska. W nowoczesnej odzieży sportowej stosuje się:

— technologie antybakteryjne, które pozwalają czuć się świeżo nawet przy wysokiej temperaturze; $w$ trakcie intensywnego treningu ciało jest chronione przed bakteriami i zanieczyszczeniami; są to technologie: coolmax, aquarius czy bodyfresh;

- technologie chłodzące, które pomagają utrzymać komfortową temperaturę ciała podczas aktywności fizycznej nawet przy wysokiej temperaturze; umożliwiają też efektywną wentylację ciała w trakcie i po ćwiczeniach;

- technologie bezszwowego łączeniainiewidocznego wykończenia pozwalające na uniknięcie obtarć i ucisków podczas treningów.

${ }^{3}$ https://www.branzafitness.com/najnowsze-trendy-aranzacja-przestrzeni-klubu-fitness/ (dostęp: 3.03.2019). 
Dodatkowo ubrania sportowe mają wyjątkowy design, ukierunkowany na określony tryb zajęć fitness. Inny jest design ubrań na jogę, inny - do uprawiania kolarstwa, inny zaś do zajęć $\mathrm{z}$ cross treningu.

Istnieją nawet blogi wskazujące i analizujące, jak powinni być ubrani użytkownicy klubów fitness na poszczególnych zajęciach sportowych. Na zajęciach bowiem trzeba być modnie ubranym - nie można przyjść zwyczajnie $\mathrm{w}$ dresie, nieodpowiednim do rodzaju wykonywanych aktywności fizycznych. Nie można mieć na sobie rzeczy w nieodpowiednich kolorach — tutaj każdy szczegół ma znaczenie. Konsument usług fitness zmienił się w ciągu ostatnich lat i oczekuje nie tylko ubrań sportowych, ale atrakcyjnych, funkcjonalnych ubrań, w których będzie czuł się swobodnie i które pozwolą na wyeksponowanie jego atutów. Interesującym zjawiskiem jest to, że design w ubraniach fitness ma znaczenie zarówno dla kobiet, jak i dla mężczyzn.

Design ubrań sportowych uwarunkowany jest wybraną strategią firmy na rynku. Są to strategie:

- budowania wizji użytkownika,

- budowania społeczności,

- budowania linii produktowych.

Budowanie wizji użytkownika $\mathrm{z}$ wykorzystaniem designu ubrań sportowych/ fitness polega na tym, że dana marka odzieżowa wraz z projektem określa, do kogo powinna trafić odzież oraz kim jest użytkownik. Przykładem jest tutaj marka Slavi produkująca designerskie ubrania fitness dla kobiet, które są: „odważne, lubiące kolory i aktywne spędzanie wolnego czasu" ${ }^{4}$. Na zdjęciach promocyjnych prezentowane są ubrania na radosnych, pewnych siebie kobietach, czyli ubrania to wizerunek, wizerunek zaś to styl życia i przynależność do określonego rodzaju kobiet.

Budowanie społeczności polega na ograniczeniu dostępności designu produktów sportowych - ograniczenie może dotyczyć klubu fitness (na przykład własnej linii ubrań firmowych) lub kuponów promocyjnych na zakup określonej linii odzieży. Przykładem jest marka Gipara, która umożliwia zakup produktów jedynie użytkownikom uczęszczającym do wybranych klubów. Mogą oni pobrać z klubu kod promocyjny 5 .

Natomiast strategia budowania linii produktowych widoczna jest szczególnie w kolarstwie terenowym lub indoorowym. Design roweru powinien być zgodny z designem ubrań użytkownika oraz designem urządzań dodatkowych (na przykład zegarka z GPS, słuchawkami itp.). Użytkownik kupuje ubrania sportowe, kierując się kluczem kolorystycznym i dopasowania designerskiego oraz marką i zgodnością designerską marki.

Design ubrań fitness to dziedzina dynamicznie się rozwijająca. Ubrania są coraz bardziej kolorowe, odróżniające się od uniformów, często noszonych w pracy.

\footnotetext{
${ }^{4}$ Slavi, https://www.branzafitness.com/slavi-to-wiecej-niz-marka-to-styl-zycia/ (dostęp: 15.11.2018).

${ }^{5}$ Gipara, https://www.giparawear.com/ (dostęp: 15.11.2018).
} 
Optymistyczny design, neonowe kolory oraz inspirujące wzory - takich ubrań poszukują użytkownicy klubów fitness.

\section{Nowe trendy w designie w fitnessie — przyszłość}

Jakie są trendy designerskie związane z fitnessem, jakich obszarów dotyczą oraz w jakim kierunku będzie rozwijał się design? Na to pytanie odpowiedzi należy poszukać w zakresie rozwoju nowych technologii oraz trendu powrotu do natury.

Według raportu firmy Erricson ConsumerLab głównym trendem w zachowaniach konsumentów będzie zmiana sposobu komunikacji oraz interakcja konsumentów z otoczeniem przy użyciu zaawansowanej technologii informacyjnej ${ }^{6}$. Zgodnie $\mathrm{z}$ tymi trendami i w odniesieniu do analizy trendów designu można stwierdzić, że przyszłość fitnessu będzie się wiązała z:

— technologią ubieralną w sporcie,

- aranżacją przestrzeni klubów fitness (design i natura),

- VR-em i designem wirtualnej rzeczywistości.

Interesująco na rynku rozwija się design technologii ubieralnej. Ubrania są atrakcyjne wizualnie oraz dzięki wbudowanym sensorom pozwalają na monitoring ciała. Projektanci, wykorzystując design technologii ubieralnej w zakresie fitnessu, opierają się obecnie na technologiach przyszłości ${ }^{7}$.

Technologie ubieralne mają też swoją ciemną stronę: urządzenia kumulują wiedzę o użytkowniku: jego imię i nazwisko, miejsca, w których przebywa, tryb życia, rytm pracy serca (co jest cenne na przykład dla branży ubezpieczeniowej), a przechowywane dane przetwarzane są w czasie rzeczywistym i kumulowane w chmurze, co w obliczu rosnącej liczby cyberzagrożeń staje się naprawdę niebezpieczne. Badacze uważają, że już w 2025 roku nie będzie istniała prywatność, albowiem za sprawą technologii ubieralnych wszystkie dane o człowieku, jako o autonomicznej jednostce i członku grupy, będą krążyć w internecie.

Prognozy International Data Corporation dla wearables zapowiadają wzrost sprzedaży o $121 \%$ (2,5 mln urządzeń) w $2020 \mathrm{roku}^{8}$.

${ }^{6}$ Erricson ConsumerLab, http://osnews.pl/10-najgoretszych-trendow-konsumenckich-na-rok-2016/ (dostęp: 20.10.2018).

7 Best fitness trackers (projekt desig future), https://topgizmo-tech.blogspot.com/2016/09/how-wearable-technology-can-impact-fashion-industry-in-future.html (dostęp: 15.11.2018)

${ }^{8}$ International Data Corporation, https://mobtech.interia.pl/akcesoria/news-technologie-ubieralne-coraz-popularniejsze-w-polsce-i-region,nId,2229861 (dostęp: 3.03.2019). 


\section{Zakończenie}

Zaprezentowane $\mathrm{w}$ artykule nowe trendy $\mathrm{w}$ designie fitness nie wyczerpują całej ich bogatej listy. Należy pamiętać, że cechami nowych trendów są ich zmienność, współwystępowanie oraz dywergencja.

Analiza pokazuje, że znacznie rośnie rola designu w fitnessie - zarówno w aranżacji przestrzeni klubów fitness, jak i projektowaniu odzieży sportowej. Obecnie samo uczęszczanie na zajęcia fitness to za mało, aby poczuć się osobą aktywną, żyjącą zgodnie ze zdrowymi trendami życia. Fitness to także design przestrzeni klubowych - głównie ze względu na to, że zmieniają się potrzeby konsumentów, a firmy sportowe prześcigają się w promowaniu nowych gadżetów lub ubrań sportowych. W celu nadążenia za zmianami firmy sportowe muszą nie tylko śledzić obecne zmiany, lecz także przewidywać przyszłościowe trendy zachowań konsumentów.

Rola designu w fitnessie jest bardzo duża - pozwala konsumentowi czuć się atrakcyjnie, umożliwia wyrażenie siebie poprzez ubranie oraz przynależność do społeczności. Trendy designerskie, zdaniem autorki, będą podążać w kierunku designu technologii ubieralnej w sporcie, aranżacji przestrzeni klubów fitness (design i natura) oraz wirtualnego designu w fitnessie VR.

\section{Bibliografia}

Alonso M.B., Plasencia O.T., Kint J. (2012), Applying Intercultural Markers Obtained from Cooking in the Design Process. The Proceedings of the International Conference on Designing Food and Designing for Food, London.

Best fitness trackers (projekt design future), https://topgizmo-tech.blogspot.com/2016/09/howwearable-technology-can-impact-fashion-industry-in-future.html.

Celaschi F., Celi M., Garcia L.M. (2011), Design: An Advanced Design Perspective, „Design Management Journal", nr 6.

DesignYourLife, https://designyourlife.pl/fashion/moda-w-wersji-fitness-czyli-jak-fajnie-sieubrac-na-silownie-jogging-i-taniec/.

Engel J.F., Blackwell R.D., Mirand P.W. (1993), Consumer Behavior, Chicago.

Gipara, https://www.giparawear.com/.

Hansen F. (1972), Consumer Choise Behavior. A Cognitive Theory, New York.

Hetzel P. (2013), Design Management et Constitution de l'Offre, Thèse de Doctorat Sciences de Gestion, Lyon.

https://www.branzafitness.com/najnowsze-trendy-aranzacja-przestrzeni-klubu-fitness/.

International Data Corporation, https://mobtech.interia.pl/akcesoria/news-technologie-ubieralnecoraz-popularniejsze-w-polsce-i-region,nId,2229861.

McFit Home of Fitness- https://www.mcfit.com/pl/firma/firma/.

MikeSport.pl, https://www.mikesport.pl/zestaw-mimo-design-flower-bike-damska-bluza-koszulkarowerowa.html.

Mozota B. de (2003), Design Management. Using Design to Build Brand Value and Corporate Innovation, New York.

Peters T. (2005), Essentials-Design. Innovate, Differentiate, Communicate, New York. 
Raport Erricson ConsumerLab, http://osnews.pl/10-najgoretszych-trendow-konsumenckich-na-rok-2016/.

Slavi, https://www.branzafitness.com/slavi-to-wiecej-niz-marka-to-styl-zycia/.

Smart\&simple, http://smart-simple.pl/.

Sztucki T. (1998), Encyklopedia marketingu, Warszawa.

Vejlgaard H. (2008), Anatomy of Trend, New York.

Zalega T. (2012), Konsumpcja. Determinanty, teorie, modele, Warszawa.

\section{Design and fitness: New trends}

\section{Summary}

Nowadays, just attending fitness classes is not enough to feel like a person living in accordance with a healthy and active lifestyle. Fitness is also a design whose role is growing dynamically mainly due to the fact that consumer needs are changing, and sports companies are outdoing themselves in promoting new gadgets or sports clothes.

In order to keep up with the changes in the society, sports must not only follow current changes, but also anticipate future trends in consumer behavior. The aim of the presented article is to analyze new trends in design in fitness and answer the following questions:

1. What is the role of design in fitness?

2. What are the design trends related to fitness, what areas are involved and in what direction will the design develop?

The article is based on the analysis of design trends related to the arrangement of the space of fitness clubs and the design of fitness clothing. 